\title{
Komunikasi Informasi Edukasi (KIE) Personal Hygiene Pada Usia Anak Sekolah Di Perumahan Budha Tzu Chi
}

\author{
Fitriani $^{1}$, Teungku Nih Farisni ${ }^{2}$, Yarmaliza ${ }^{3}$, Fitrah Reynaldi ${ }^{4}$, \\ Veni Nella Syahputri ${ }^{5}$. \\ ${ }^{1234}$ Ilmu Kesehatan Masyarakat, Universitas Teuku Umar \\ Email: fitriani@utu.ac.id \\ Email : teungkunihfarisni@utu.ac.id \\ Email : yarmaliza@utu.ac.id \\ Email : fitrahreynaldi@utu.ac.id \\ 5Ilmu Administrasi Negara, Universitas Teuku Umar \\ Email : veninellasyahputri@utu.ac.id
}

\begin{abstract}
Unfavorable personal hygiene at the age of elementary school children will be at risk of experiencing various health problems. Personal hygiene for elementary school aged children in the Budha Tzu Shi neighbourhood is still not good. The method used in this community dedication is carried out in two stages, first is to provide IEC to children about the importance of brushing teeth, cutting nails, bathing using soap and shampoo, wearing clean clothes and washing hands with soap to prevent disease, and the second stage is the practice of brushing teeth, cutting nails and the 7 steps of washing hands. The results of the assessment of this community dedication activities showed that the level of participants' knowledge increased by $93 \%$ or 28 people. It can be concluded that the increase knowledge of particpants in this community dedication is closely retated to the ability of practicing the 7 steps of washing hands properly and how to brush their teeth appropriately.
\end{abstract}

Keywords: Communication, Information, Education, Knowledge

Abstrak

Personal hygine yang kurang baik pada usia anak sekolah dasar akan berisiko mengalami berbagai gangguan kesehatan. Personal hygiene pada anak usia sekolah dasar di perumahan Budha Tzu Shi menunjukkan masih kurang baik. Metode yang digunakan dalam pengabdian masyarakat ini dilakukan dengan dua tahap, pertama adalah dengan memberikan KIE pada anak-anak tentang pentingnya menggosok gigi, memotong kuku, mandi menggunakan sabun dan shampoo, memakai pakaian yang bersih serta mencuci tangan pakai sabun untuk mencegah terjadinya penyakit, dan tahap kedua adalah praktek gosok gigi, memotong kuku dan 7 langkah cuci tangan. Hasil penilaian dari kegiatan pengabdian menunjukkan tingkat peningkatan pengetahuan peserta meningkat sebesar 93, \% atau 28 orang. Dapat disimpulkan bahwa dari peningkatan pengetahuan peserta pengabdian berkorelasi dengan kemampuan mepraktikkan 7 langkah cuci tangan dengan tepat dan cara menggosok gigi dengan baik.

Kata Kunci: Komunikasi, Informasi, Edukasi, Pengetahuan

\section{PENDAHULUAN}

Penyakit yang berhubungan dengan kebersihan diri merupakan masalah kesehatan utama pada anak usia sekolah dasar, seperti gosok gigi yang baik dan benar, kebiasaan cuci tangan pakai sabun, dan kebersihan diri. Penyakit yang 
sering muncul diantaranya adalah kecacingan, diare, ,sakit gigi dan berbagai penyakit kulit (Saputra, 2013)

Personal hygiene (Kebersihan diri) merupakan kebutuhan dasar manusia yang harus senantiasa terpenuhi. Personal hygiene merupakan perawatan diri sendiri yaang dilakukan untuk mempertahankan kesehatan, baik secara fisik maupun psikologis (Lindsay Dingwall., 2016). Ruang lingkup personal hygiene sendiri ada tujuh, yaitu perawatan kulit kepala dan rambut, mata, hidung, telinga, kuku kaki dan tangan,organ reproduksi dan perawatan secara keseluruhan. Personal hygiene yang baik akan meminimalkan pintu masuk (port de entry) mikroorganisme yang ada dilingkungan sehingga dapat mencegah seseorang terkena penyaki (Kemenkes RI, 2012)

Anak-anak pada usia 6 - 11 tahun merupakan usia anak yang masih duduk di bangku sekolah dasar dan sedang mengalami perkembangan secara sosial (Abdoerrachman, 2014) . Pada masa ini anak-anak mulai belajar menyesuaikan diri dengan lingkungan sekitar dan mereka akan cenderung lebih aktif untuk mengembangkan rasa ingin tahunya yang besar serta bergaul bersama teman sebayanya. Karena hal tersebutlah anak-anak cenderung mengabaikan kebersihan tubuh, perilaku sehat, dan kebiasaan bersihnya (Isro'in, L., dan Andarmoyo, 2012).

Rendahnya kesadaran dan minimnya pengetahuan tentang kesehatan pada anak usia ini, membuat mereka masih membutuhkan pengawasan dan bimbingan dari orang terdekat atau orang yang berpengaruh untuk melakukan personal hygiene-nya. Jika anak-anak tidak melakukan personal hygiene dengan tepat maka mereka akan berisiko mengalami berbagai gangguan kesehatan (Notoatmodjo S., 2012). Daya tahan tubuh anak-anak yang belum cukup kuat dapat membuat anak-anak lebih rentan terhadap serangan dan infeksi kuman dari luar tubuh (Hidayat, 2011).

Personal hygiene yang tidak baik akan mempermudah tubuh terserang berbagai penyakit, seperti penyakit kulit yaitu skabies, penyakit infeksi, penyakit mulut dan gigi, dan penyakit saluran cerna atau bahkan dapat menghilangkan fungsi bagian tubuh tertentu, seperti halnya kulit. Pendidikan mengenai personal hygiene diperkenalkan melalui program Usaha Kesehatan Sekolah (UKS) yang bertujuan untuk meningkatkan kemampuan hidup sehat peserta didik dan derajat kesehatan peserta didik, 
serta menciptakan lingkungan sekolah yang sehat sehingga tercapai pertumbuhan dan perkembangan yang optimal dalam upaya membentuk manusia Indonesia yang sehat. Sekolah sebagai institusi masyarakat yang terorganisasi dengan baik merupakan sarana yang efektif untuk pemberian pendidikan kesehatan dalam upaya mengubah perilaku dan kebiasaan anak-anak sekolah agar menjadi lebih sehat. Pendidikan kesehatan mengenai cara menyikat gigi bagi anak-anak perlu diberikan contoh suatu model yang baik serta dengan teknik yang sesederhana mungkin. Penyampaian pendidikan kesehatan gigi dan mulut pada anak-anak harus dibuat semenarik mungkin, antara lain melalui penyuluhan yang atraktif, sehingga anak dapat mengalami kemajuan dari membuat penilaian berdasarkan apa yang mereka lihat (pemikiran perseptual) sampai membuat penilaian berdasarkan alasan mereka (pemikiran konseptual), tentunya tanpa mengurangi isi pendidikan (Wita Apriani, 2014).

Perumahan Budha Tzu Chi merupakan salah satu wilayah relokasi di Kabupaten Aceh Barat pasca tsunami tahun 2006. Berdasarkan data kesehatan pada anak- anak menunjukkan masih tingginya kejadian diare dan angka sakit gigi. Studi pendahuluan melalui observasi dan wawancara pada 5 anak di perumahan Budha Tzu Shi menunjukkan personal hygiene yang kurang baik pada anak - anak, dimana 4 anak tidak mengetahui cara menjaga kebersihan diri secara menyeluruh, tidak mencuci tangan dengan sabun serta kuku mereka panjang dan kotor. Keadaan ini disebabkan pengetahuan mereka yang masih rendah tentang praktik personal hygiene yang baik.

Berdasarkan analisis situasi tersebut pentingnya dilakukan Komunikasi Informasi Edukasi (KIE) pada usia anak sekolah dasar di perumahan Budha Tzu Shi. KIE personal Hygine pada usia anak sekolah akan memebentuk kebiasaan personal hygine yang baik sejak dini agar tercapai kesehatan individu yang lebih baik pada masa yang akan dating (Maulana, H., Heri, D., 2012). Tujuan kegiatan pengabdian ini untuk meningkatkan prakti perilaku personal hygiene yang baik pada usia anak sekolah dasar di perumahan Budha Tzu Shi.

\section{METODE PELAKSANAAN}

Metode yang digunakan dalam pengabdian masyarakat ini dilakukan dengan dua tahap, pertama adalah dengan memberikan KIE pada anak-anak 
mengenai pentingnya menggosok gigi, memotong kuku, mandi menggunakan sabun dan shampoo, memakai pakaian yang bersih serta mencuci tangan pakai sabun untuk mencegah terjadinya penyakit, dan tahap kedua adalah praktek gosok gigi, memotong kuku dan 7 langkah cuci tangan dengan pendampingan oleh tim pengabdi.

Pemberian KIE dengan metode ceramah di lakukan dengan alat bantu pendukung seperti: poster, infokus projector dan pemutaran video personal hygiene. Materi pelatihan yang diberikan meliputi: manfaat gosok gigi dan cuci tangan pakai sabun, waktu yang baik menggosok gigi dan mencuci tangan, cara menyikat gigi dan lidah yang benar, serta cara mencuci tangan. Peserta pengabdian ini berjumlah 30 siswa(i) yang tingkat sekolah dasar. Kegiatan pengabdian dilakukan di Aula perumahan Budha Tzu Shi.

Penilaian tingkat keberhasilan kegiatan ini dilakukan melalui pretest dan postes terhadap pengetahuan peserta pengabdian.

Manfaat dari kegiatan pengabdian masyarakat ini adalah anak usia pra sekolah mendapatkan pengetahuan tentang cara menggosok gigi yang benar dan 7 langkah cuci tangan pakai sabun, menumbuhkan kesadaran hidup sehat sejak dini pada anak usia pra sekolah, membangun kebiasaan anak usia pra sekolah untuk dapat menerapkan cara menggosok gigi dan mencuci tangan dengan benar dalam kehidupan sehari-hari, serta melatih anak usia sekolah untuk selalu menjaga kesehatan mulut dan tangan (Putri, R.M, Maemunah, N., Rahayu, 2016). Kegiatan pengabdian masyarakat ini diharapkan memiliki dampak yang positif, yaitu meningkatnya pengetahuan dan keterampilan anak usia sekolah mengenai cara menggosok gigi dan mampu mencuci tangan 7 langkah dengan sabun dengan benar (Mardliyah, 2014).

\section{HASIL DAN PEMBAHASAN}

Pelaksanaan kegiatan pengabdian masyarakat ini berjalan sesuai dengan yang diharapkan. Pelaksanaan Kegiatan pengabdian dilaksanakan ini dibantu oleh beberapa mahasiswa. Sebelum dilakukan kegiatan pengabdian, seluruh peserta diberikan kuisioner sebagai bentuk penilaian awal (pretest) terhadap pengetuan personal hygine mereka. Personal hygiene merupakan upaya yang dilakukan oleh individu untuk menjaga kebersihan pribadinya agar terhindar dari penyakit. Pemenuhan personal hygiene dipengaruhi bebagai faktor seperti faktor budaya, nilai sosial individu atau keluarga, pengetahuan tentang 
personal hygiene serta persepsi terhadap perawatan diri. Dikaitkan dengan anak usia pra sekolah, personal hygine memegang peranan penting. Masih rendahnya daya tahan tubuh anak di usia ini memungkinkan banyaknya penyakit yang akan diderita jika personal hygine anak tidak diperhatikan. Orang tua memegang peranan penting dalam membantu personal hygiene anak usia pra sekolah.

Pentingnya pola asuh orang tua dalam meningkatkan kesehatan anak merupakan suatu upaya yang sangat mendasar melalui pembinaan lingkungan, kebersihan perorangan, dan pendidikan kesehatan sejak dini. Dalam melakukan tugas dan kewajibannya dalam mengasuh anak tidak terlepas dari unsur-unsur yang menyertai, yaitu perilaku dan cara yang diterapkan. Pola asuh orang tua ke pada anaknya sangat mempengaruhi perilaku anaknya. Orang tua adalah guru pertama untuk anakanaknya, yang berarti orang tua tersebut memiliki kewajiban untuk memberikan pengajaran atau pendidikan yang baik untuk anaknya. Kemudian, jika orangtua / keluarga yang terlalu sibuk dengan pekerjaan, mencari materi dan kesibukan atau urusan lain yang akhirnya lupa untuk mendidik dan mengasuh anak dengan baik. Dengan begitu terserah anak itu mau tumbuh dan berkembang menjadi apa. Situasi keluarga yang tidak mendukung pengembangan karakter terhadap anak, kurangnya perhatian dan keterbukaan antara orang tua/ keluarga dengan anaknya menyebabkan anak mencari pelarian ke hal yang negatif.

Anak dikenalkan tentang kebersihan badan dan bertanggungjawab atas kebersihan badannya secara mandiri (Graha, 2008). Pola asuh merupakan seluruh perlakuan orang tua yang diterapkan pada anak. Mengasuh dan membina anak dirumah merupakan kewajiban bagi setiap orang tua dalam usaha membentuk pribadi anak. Pola asuh orang tua terdiri dari tiga jenis yakni pola asuh otoriter, permisif, dan demokratis.

Orang tua memiliki peranan dalam mendidik, menjadi panutan bagi anak, memberi nasehat, serta mengingatkan anak untuk selalu menjaga kebersihan diri. Orang tua perlu menekankan pentingnya menjaga personal hygiene kepada anak sejak dini. Anak dibiasakan untuk selalu membersihkan badan hingga tahu apa yang harus dilakukan semestinya sejak kecil. Perlakuan orang tua yang demikian dapat menjadikan anak selalu menjaga kebersihan badannya, dan 
anak terbiasa untuk tidak bersih memberikan kenyamanan, mempunyai badan yang kotor (Graha, 2008). Berbagai manfaat serta dapat meningkatkan yang dapat dirasakan oleh anak apabila selalu menjaga personal hygiene, seperti: terhindar dari berbagai penyakit, tubuh yang kepercayaan diri anak. Kurangnya menjaga kebersihan diri dapat menimbulkan berbagai masalah kesehatan apabila tidak diatasi segera.

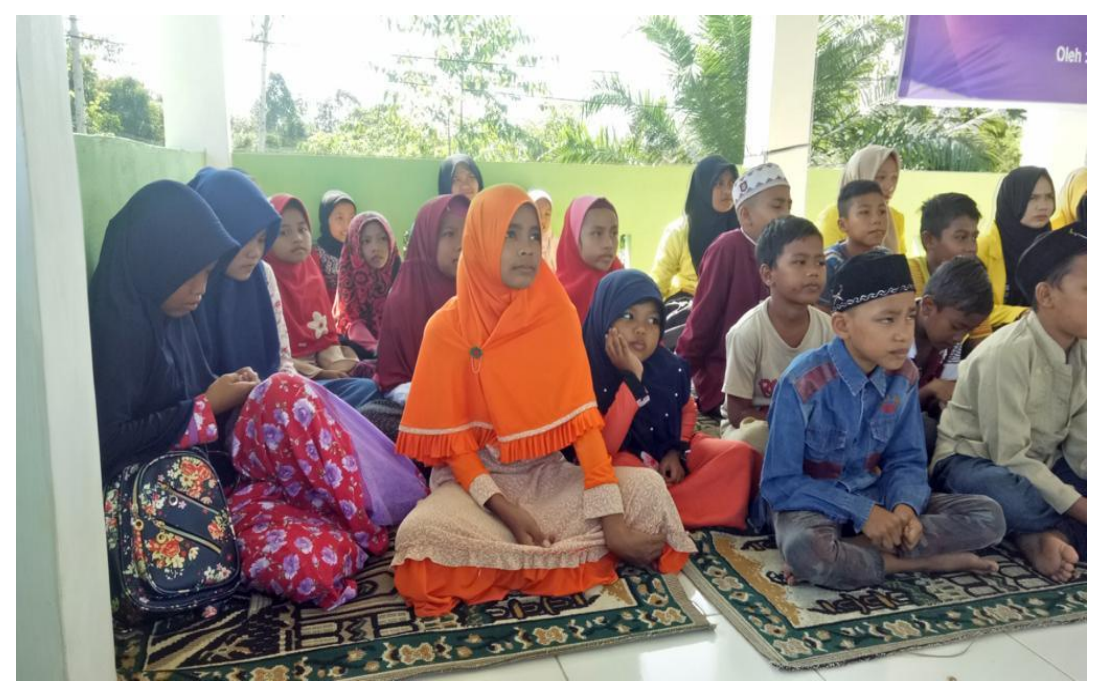

Gambar 1. Peserta Kegiatan Pengabdian

Berikut ini Kegiatan yang telah dilaksanakan oleh Tim Pengabdian Kepada Masyarakat:

a. Kegiatan pada tahap pertama ini di awali dengan pembukaan kegiatan dan pemberian KIE terhadap peserta yang meliputi materi : a) Menggosok gigi yang benar ; materi yang disampaikan pada kegiatan ini meliputi frekuensi menyikat gigi dalam sehari, langkah- langkah menyikat gigi dan syarat penggunaan sikat gigi yang baik. secara keseluruhan peserta kegiatan sudah mempraktikkan menggosok gigi dalam kehidupannya, akan tetapi mereka tidak mengetahui bagaimana cara menggosok gigi yang benar sehingga gigi kurang bersih dan bisa menyebabkan gigi berlubang, mengikisnya email gigi akibat cara menggosok gigi yang tidak benar. Pemberian KIE ini dibantu dengan media infokus projector yang menampilkan langkah - langkah menggosok gigi yang baik serta menampilkan video bahaya gigi 
kotor. b) Memotong kuku, materi yang disampaikan yaitu manfaat memotong kuku dan bahaya kuku panjang dan kotor. Untuk memudahkan penyerapan edukasi tentang manfaat kuku bersih digunakan alat bantu poster yang menunjukkan ilustrasi bakteri yang bersarang saat kuku kotor. c) Mencuci tangan pakai sabun, materi yang disampaikan yaitu 7 langkah mencuci tangan. Pada kegiatan ini agar memudahkan pemahaman peserta digunakan alat bantu poster dan peserta dimotivasi dengan menyanyikan lagu 7 langkah cuci tangan. Selain menggosok gigi, mencuci tangan dengan sabun merupakan salah satu dari personal hygiene yang perlu diajarkan kepada anak sejak dini. Mencuci tangan pakai sabun adalah salah satu tindakan kebersihan dengan cara membersihkan tangan dan jari jemari menggunakan air dan sabun oleh manusia untuk menjadi bersih dan memutuskan mata rantai mikroorganisme sebagai sumber penyakit. Mencuci tangan dengan sabun dikenal juga sebagai salah satu upaya pencegahanpenyakit, hal ini dilakukan karena tangan seringkali menjadi pembawa mikroorganisme dan menyebabkan mikroorganisme ini dapat berpindah dari satu orang ke orang lain, baik dengan kontak langsung ataupun kontak tidak langsung (menggunakan permukaan- permukaan lain seperti handuk, gelas, dan lainsebagainya) Kegiatan pada tahap pertama ini dinilai sangat efektif terhadap peningkatan pengetahuan peserta, dimana setelah kegiatan peserta dengan mudah bisa menyebutkan cara menggosok gigi yang benar, bahaya bagi kesehatan apabila kuku panjang dan kotor serta mereka sangat lugas menyebutkan langkah - langkah cuci tangan yang benar.

b. Kegiatan kedua yaitu praktik 7 langkah cuci tangan dan praktik menyikat gigi. Sebelum dilakukan kegiatan praktik, masing- masing peserta dibagikan paket yang berisi alat untuk menyikat gigi dan sabun untuk mencuci tangan. Pelaksanaan praktik sikat gigi didampingi oleh tim pengabdi dan juga dibantu oleh beberapa mahasiswa. Praktik sikat gigi ini dilakukan dengan antusias oleh peserta pengabdian, dan mereka mampu mempraktikkan sikat gigi dengan baik yang dimulai dengan langkah - langkah berikut ini : Berkumur terlebih dahulu, kemudian dilanjutkan dengan menyikat gigi bagian 
depan, menyikat gigi bagian dalam, menyikat gigi bagian samping, menyikat gigi geraham, dan berkumur kembali. Praktik 7 langkah cuci tangan dilakukan dengan tepat oleh seluruh peserta, serta dilakukan dengan riang gembira karena diiringi dengan nyanyian cuci tangan. Mencuci tangan dengan air saja lebih umum dilakukan tetapi tidak efektif menjaga kesehatan dibandingkan mencuci tangan dengan sabun. Agar efektif WHO (2009) telah menetapkan langkahlangkah mencuci tangan pakai sabun sebagai berikut : membasahi kedua tangan dengan air mengalir, beri sabun secukupnya, menggosokkan kedua telapak tangan dan punggung tangan, menggosok sela-sela jari kedua tangan, menggosok keduatelapak tangan dengan jari-jari rapat, jari-jari tangan dirapatkan sambil digosok ke telapak tangan, tangan kiri ke kanan, dan sebaliknya,menggosok ibu jari secara berputar dalam genggaman tangan kanan, dan sebaliknya, menggosokkan kuku jari kanan memutar ke telapak tangan kiri, dan sebaliknya, basuh dengan air, dan mengeringkan tangan Secara keseluruhan peserta mampu melakukan praktik 7 langkah cuci tangan, yaitu : 1) Membasahi tangan dengan air dan tuangkan sabun ke telapak tangan. 2) Mengusap kedua telapak tangan dengan gerakan memutar, 3) Metakkan telapak tangan kanan di atas punggung tangan kiri dan kaitkan jari-jari kedua tangan sambil diusap ke atas dan ke bawah. 4) Menangkupkan kedua telapak tangan sambil mengaitkan jari-jari lalu gosok sela-sela jari. 5) Meletakkan buku-buku jari tangan kanan di telapak tangan kiri dan sebaliknya, lalu gosok dengan arah memutar.6) Menggenggam ibu jari tangan kiri menggunakan tangan kanan dan sebaliknya lalu gosok dengan arah memutar. 7) Membentuk tangan kanan menjadi bentuk kuncup, lalu gosok-gosok kuku di atas permukaan telapak tangan kiri dan sebaliknya. 


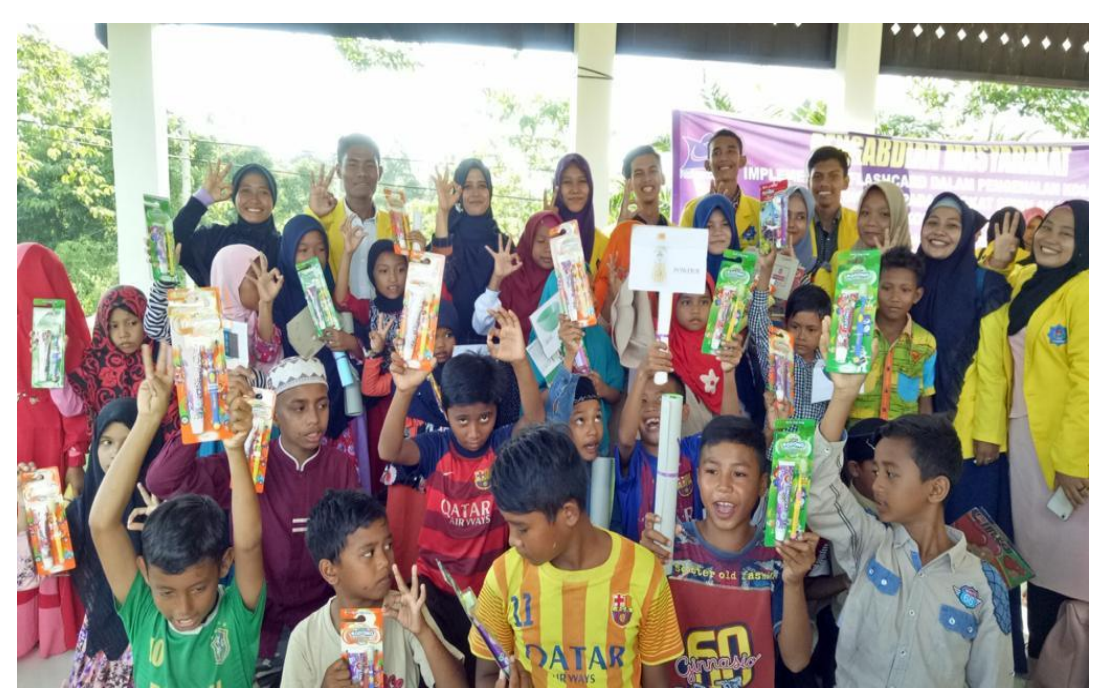

Gambar 2. Foto bersama setelah kegiatan selesai

Hasil penilaian keberhasilan kegiatan pengabdian ini dapat ditunjukkan pada tabel 1 berikut ini :

\begin{tabular}{lllll}
\hline $\begin{array}{c}\text { Pengetahuan Personal } \\
\text { Hygiene }\end{array}$ & N & Baik & \multicolumn{1}{c}{ Kurang Baik } \\
\hline & 5 & 16,1 & 25 & n \\
\hline 1 Sebelum KIE & 28 & 93,3 & 2 & 83,3 \\
2 Sesudah KIE & & &
\end{tabular}

Berdasarkan tabel 1 diatas menunjukkan distribusi frekuensi pengetahuan pesserta tentang personal hygine sebelum KIE yaitu dengan tingkat pengetahuan baik 5 orang $(16,6 \%)$ sedangkan pengetahuan kurang baik 25 orang (83,3\%). Setelah dilakukan KIE terjadi peningkatan pengetahuan yaitu sebesar 28 orang. $(93,3)$.

\section{PENUTUP}

Berdasarkan hasil kegiatan pengabdian masyarakat dapat disimpulkan bahwa dengan adanya peningkatan pengetahuan peserta pengabdian yang memberikan dampak positif terhadap prilaku peserta dalam menerapkan 7 langkah cuci tangan dengan tepat dan cara menggosok gigi dengan baik. Saran dari hasil kegiatan ini ; pemberian KIE personal hygine pada anak usia sekolah dasar bisa dillanjutkan pada kelompok sasaran yang lebih besar.

\section{DAFTAR PUSTAKA}

Abdoerrachman (2014) 'Buku Kuliah Kesehatan Anak. Jakarta : Infomedika'. 
Hidayat, A. A. A. (2011) ‘Pengantar Ilmu Keperawatan Anak. Jakarta : Salemba Medika.'

Isro'in, L., dan Andarmoyo, S. (2012) 'Personal hygiene. Jakarta: Graha Ilmu.'

Lindsay Dingwall. (2016) 'Hygiene Personal Keterampilan Klinis Perawat. Jakarta'.

Mardliyah (2014) 'Pola Asuh Orang Tua Sebagai Faktor Penentu Kualitas Pemenuhan Kebutuhan Dasar Personal Hygiene Anak Usia 6- 12 Tahun.', Jurnal Ners dan Kebidanan Indonesia, 2(2), pp. 86-92.

Maulana, H., Heri, D., J. (2012) 'Promosi Kesehatan. Jakarta : EGC'.

Notoatmodjo S. (2012) 'Ilmu Perilaku Kesehatan. Jakarta: Rineka Cipta'.

Putri, R.M, Maemunah, N., Rahayu, W. (2016) 'Pemeriksaan Pertumbuhan dan Personal Hygiene Anak Pra Sekolah di RA Pesantren Al Madaniyah.', Jurnal Akses Pengabdian Indonesia, 1(1), pp. 55-64.

RI, K. K. (2012) 'Panduan Promosi Kesehatan di Sekolah. Jakarta'.

Wita Apriani (2014) 'Hubungan Pola Asuh Orang Tua dengan Perkembangan Interaksi Sosial Anak Prasekolah di Tam PAUD AR-Rohim Palembang. Skripsi STIKes Muhammadiyah Palembang'. 